\title{
Effect of high-pressure rolling followed by laser processing on mechanical properties, microstructure and residual stress distribution in multi-pass welds of 304L stainless steel
}

\author{
Jibrin Sule $^{1} \cdot$ Supriyo Ganguly ${ }^{1} \cdot$ Wojciech Suder $^{1} \cdot$ Thilo Pirling $^{2}$
}

Received: 14 September 2015 / Accepted: 21 December 2015 /Published online: 18 January 2016

(C) The Author(s) 2016. This article is published with open access at Springerlink.com

\begin{abstract}
Multi-pass fusion welding by a filler material (wire) is normally carried out to join thick steel sections used in most engineering applications. Multiple thermal cycles from a multi-pass weld resulted in a variable distribution of residual stress field across the weld and through the thickness. Presence of tensile residual stresses can be detrimental to the integrity and the service behaviour of the welded joint. In addition to a complex distribution of residual stress state, multipass welds also form dendritic grain structure, which are repeatedly heated, resulting in segregation of alloying elements. In this research, microstructural refinement with modification of residual stress state was attempted by applying post-weld cold rolling followed by laser processing and then cold rolling. The residual stress was determined non-destructively by using neutron diffraction. Post-weld cold rolling followed by laser processing was carried out to induce recrystallization of the cold rolled grains. Microstructural characterisation indicates a significant grain refinement near the capping pass. However, post-weld cold rolling followed by laser processing reinstates the lock-in stress. In this study, it was demonstrated that a complete recrystallized microstructure with compressive state of stress can be formed when a further cold rolling is applied on the laser processed, recrystallized microstructure.
\end{abstract}

Jibrin Sule

jibrinsule2005@yahoo.com

1 Welding Engineering and Laser Processing Centre, Cranfield University, Bedford MK43 0AL, UK

2 Institut Max von Laue-Paul Langevin, 6 rue Jules Horowitz, BP156, 38042 Grenoble, France
Keywords Multi-pass welds · Microstructure $\cdot$ Residual stress $\cdot$ Rolling $\cdot$ Laser processing

\section{Introduction}

AISI 304L stainless steels are extensively used in industries due to their superior low-temperature toughness in addition to high corrosion resistance. These materials exhibit an attractive combination of good strength, ductility, toughness, excellent corrosion resistance and good weldability $[1,2]$. Due to these attributes, austenitic stainless steels are used in a range of industries such as thermal power generation, biomedical and petrochemical, automotive and chemical engineering [3]. In the structural joining applications, it is essential to form strong joints that allow transfer of load between the different steel components. Welding is generally the preferred joining method since it forms an integrated structure. Welding also alleviates corrosion problems often associated with fasteners. This process creates most robust joint to the application.

However, numerous factors make the areas around welded joints common sites for initiation of failure (especially fatigue failure). Welding often introduces defects into the material, from which fatigue cracking can initiate.

This fatigue and stress corrosion cracking are surfacesensitive phenomena [4], and often initiation of such crack depends on surface residual stress state. In large thickness, multi-pass welding process is normally employed which causes a variable distribution of residual stress field. In order to understand the fracture toughness of critical components, it is vital to characterise the stress profile [5].

Thermal stresses generated in welds are undesirable but inevitable during fusion welding. The distributions of residual stress in the weld are generally tensile in the longitudinal (along-weld) direction close to the weld line and, further away 
from the weld centre line, the tensile longitudinal stresses is balanced by compressive longitudinal residual stresses [6]. This tensile residual stress can be additive to operational loads and, as such, they can increase the driving force for fracture [7] and accelerate the degradation of the material while in service [8].

The presence of tensile residual stresses has been reported to accelerate stress corrosion cracking and fatigue crack growth rates [9] which are detrimental to the integrity and the service behaviour of the welded joint. Mullins and Gunnars [10] reported the effect of stress on material using finite element models of two multi-pass, stainless steel girth welds. In addition, sensitization of the weldments is one of the potential problems in the welding of austenitic stainless steels. Sensitization leads to degradation of corrosion resistance as well as the mechanical properties of the welded samples [11]. The sensitised microstructure along with presence of residual stress will hasten damage of a component while in service.

Significant research has been carried out on how to mitigate the effects of residual stress in stainless steels. For example, the use of low-temperature stress relief with slow cooling and solution annealing to mitigate the effects of residual stress was carried out by Panchal [12]. Others include vibratory stress relief (VSR) which is a process to reduce and redistribute the internal residual stresses of welded stainless steel structures by means of post-weld mechanical vibration [13]. The use of water-shower cooling during welding to reduce tensile residual stress in austenitic stainless steel welding has also been reported by Yanagida and Koide [14].

Although the application of rolling to reduce the residual stress in welding has been reported, the used synchronous rolling during welding (SRDW) along both sides of the weld to prevent weld hot cracking in high-strength aluminium alloy 2024-T4 was reported by Liu et al. [15]. Altenkirch et al. [16] investigated the efficacy of applying rolling pressure along the weld line in thin butt welds produced using friction stir welding (FSW) as a means of controlling the welding residual stresses. Coules et al. [17] use a localised high-pressure rolling of gas metal arc welds to relieve residual stresses in thin plate. The application of post-weld cold rolling followed by laser processing and then cold rolled on multi-pass welds of stainless steel is a novel approach.

In addition to a complex distribution of residual stress state, multi-pass welds also form dendritic grain structure, which are repeatedly heated, resulting in segregation of alloying elements. Dendritic grain structure is weaker and segregation of alloying elements would result in formation of corrosion microcells as well as reduction in overall corrosion prevention due to depletion of alloying elements. Modification of the material's microstructure by heat treatment can have a dramatic effect on hardness and fracture toughness in both the fusion region and the heat-affected zone (HAZ), which consequently affects fatigue properties greatly.
In our previous work $[18,19]$, the laser processing was in transient heating mode and the result shows that very minimal grains refinement were observed at the cap pass of multi-pass welds when post-weld cold rolling sample was followed by laser processing. However, the post-weld cold rolling followed by laser processing at the cap pass resulted in reinstated aswelded residual stress state profile.

Following this observation, different laser processing route was identified which is the main objective of this investigation. The new laser processing involves applying thermal energy for a prolonged period which would ensure full recrystallization of the grain structure. This would be followed by another cold rolling to redistribute and eliminate the tensile residual stress state which would form in laser processing.

The aim of this research is to apply this novel technique of high-pressure rolling followed by laser processing which will be subsequently followed by another high-pressure rolling to modify the mechanical properties, microstructure, and residual stress of multi-pass welds of 304L austenitic stainless steel.

\section{Experimental procedures}

\subsection{Material}

In this study, the material used was AISI 304L grade of austenitic stainless steel plate (12 mm thick) and the filler material used was Lincoln MIG 308L Si of $1.0 \mathrm{~mm}$ nominal diameter. Table 1 shows the chemical compositions of the AISI 304L grade, while Table 2 shows the chemical compositions of the filler material used. Ninety-eight percent $\mathrm{Ar}$ and $2 \% \mathrm{O}_{2}$ shielding gas were used at a flow rate of $301 \mathrm{~min}^{-1}$. The dimension of the test piece is $(300 \times 150 \times 12) \mathrm{mm}$. The bevel was filled with three welding passes. The setup is shown in Fig. 1.

\subsection{Experimental techniques}

Figure 2 shows the experimental steps of this research. Firstly, welding was carried out by using tandem GMAW DC process; secondly, post-weld cold rolling was performed using an in-house rolling device with rolling load of $100 \mathrm{kN}$; third stage was the post-weld cold rolling followed by laser processing using $8 \mathrm{~kW}$ (peak power) continuous wave (CW) fibre laser; and finally, a cold rolled after the post-weld cold rolling followed by laser processing as shown in the flow chart.

\subsubsection{Welding}

Tandem gas metal arc welding process was used. The welding parameters are shown in Table 3. 
Table 1 Chemical composition (wt $\%$ ) of 304L austenitic stainless steel plate

\begin{tabular}{llllllllllllll}
\hline Element & $\mathrm{C}$ & $\mathrm{Si}$ & $\mathrm{Mn}$ & $\mathrm{Cr}$ & $\mathrm{P}$ & $\mathrm{Mo}$ & $\mathrm{Ni}$ & $\mathrm{Al}$ & $\mathrm{S}$ & $\mathrm{Cu}$ & $\mathrm{Nb}$ & $\mathrm{Ti}$ \\
\hline $\mathrm{Wt} \%$ & 0.021 & 0.36 & 1.48 & 18.2 & 0.022 & 0.15 & 8.10 & $<0.01$ & $<0.005$ & 0.19 & 0.01 & $<0.01$ \\
\hline
\end{tabular}

The heat input was also calculated using Eq. 1.

Heat input $=($ Power $\times$ efficiency $) /($ Travel speed $)$

And, power $=$ current $\times$ voltage

The efficiency used in this research is $80 \%$ of the total heat input according to Kou [20].

\subsubsection{High-pressure rolling}

Post-weld cold rolling was carried out using the in-house rolling device which was capable of rolling with a constant force. The principle of operation of this machine was explained elsewhere [18]. This in-house rolling device is only capable of rolling with a constant force of $200 \mathrm{kN}$. Hence, the rolling load of $100 \mathrm{kN}$ with a constant travel speed of $11.7 \mathrm{~mm} \mathrm{~s}^{-1}$ was used. The roller used was made from hardened BS 4659 BH13 tool steel, which has an effective width of $30 \mathrm{~mm}$ and the diameter of $100 \mathrm{~mm}$. The profile of the roller was a flat roller as shown in Fig. 3 which was applied on the top of the weld metal, and the roller did not touch the plate surface on either side of the weld.

\subsubsection{Laser processing}

Laser processing was carried out in two phases. The laser processing in the first phase was in transient heating mode, while the second phase of the laser processing was based on the observation made in the first phase of the experiment. The second phase involves applying thermal energy for a prolonged period which would ensure full recrystallization of the grain structure.

In the first phase, the $\mathrm{CW}$ laser was used as explained in our previous work [19]. The laser beam was transmitted to the laser head through an optical fibre of $300 \mu \mathrm{m}$ diameter. Laser beam was then collimated by a lens of $125 \mathrm{~mm}$ focal length and then focused using a $250 \mathrm{~mm}$ focussing lens. This would produce a spot size of $0.61 \mathrm{~mm}$ at the focal point. However, the laser beam in this specific experiment was used to gradually increase the temperature by controlled rate and a

Table 2 Chemical composition (wt\%) of the MIG 308L Si (filler material)

\begin{tabular}{llllllll}
\hline Element & $\mathrm{C}$ & $\mathrm{Si}$ & $\mathrm{Mn}$ & $\mathrm{Cr}$ & $\mathrm{P}$ & $\mathrm{Mo}$ & $\mathrm{Ni}$ \\
\hline $\mathrm{Wt} \%$ & 0.01 & 0.75 & 1.6 & 20 & 0.015 & 0.20 & 10 \\
\hline
\end{tabular}

defocussed beam of $20 \mathrm{~mm}$ spot size was used to reduce the power density at the spot. The laser head was tilted at $10^{\circ}$ angle to avoid any back reflection which could damage the lens (Fig. 4a).

In the second phase, the same CW laser was used as in the first phase, but instead of transient heating mode, the postweld cold rolling samples were gradually heated by controlling the laser power with a large beam diameter of $110 \mathrm{~mm}$. The post-weld cold rolling samples were heated to $800^{\circ} \mathrm{C}$. It worth mentioning that the purpose of laser processing is to induce recrystallization after cold rolling of the weld metal. Figure $4 \mathrm{~b}$ shows the schematic diagram for the second phase laser setup. The laser head was positioned at $25^{\circ}$ angle to avoid any back reflection which could damage the lens.

\subsection{Experimental measurement}

In this experimental measurement, determination of the Weld thermal cycles, microstructure, residual stress measurement, hardness, and tensile test was performed.

\subsubsection{Determination of weld thermal cycles}

Thermocouples were used to measure the thermal cycle of the weld metal with the aid of a Scopecorder 750 instrument. Two K-type thermocouples were used. The first thermocouple was place at $1 \mathrm{~mm}$ below the capping pass, while the second thermocouple was placed at the root pass which is approximately $9 \mathrm{~mm}$ below the capping pass through the hole drilled from backing bar to the weld metal. Figure 5 shows the sketch how the thermocouples were placed.

\subsubsection{Microstructure and hardness test}

The welded samples were cut, ground, and polished according to standard metallographic procedures for microstructural observations and micro hardness tests. The Zwick Roell micro hardness testing machine was used in measuring the hardness of all the samples. For micro hardness testing, 500-g load and 5-s dwell time were applied. Across and along the multi-pass weld metal, the hardness scanning was done with an interval of $0.5 \mathrm{~mm}$ between consecutive points. 


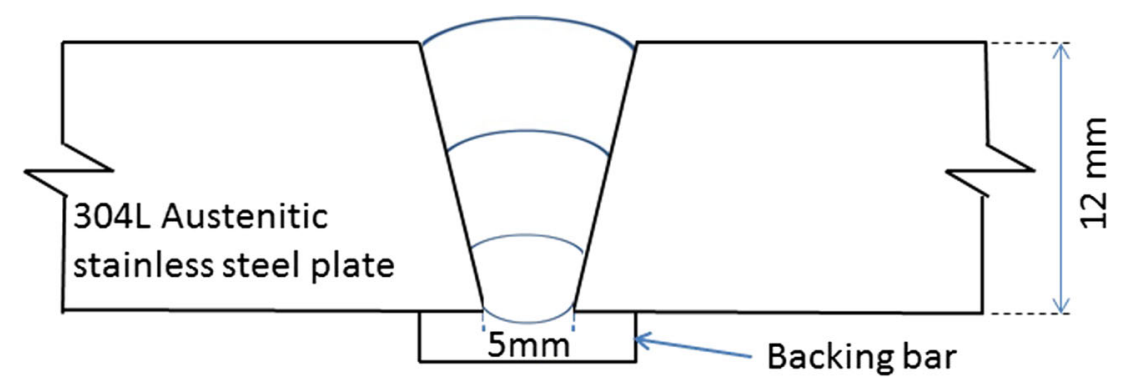

Fig. 1 304L austenitic stainless steel plate showing welding preparation

\subsubsection{Measurement of residual stresses using neutron diffraction}

Owing to the neutron beam's unique deep penetration and three-dimensional mapping capabilities [21], these neutrons penetrate even iron to a depth of several tens of millimetres; hence, it allows for non-destructive measurement of the strain in steel materials [22]. Majority of neutron strain-scanning instruments use a nuclear reactor as the neutron source, which produces a continuous flux of neutrons over a range of wavelengths. Current examples of constant flux instruments include Strain Analyser for Large and Small Scale Engineering Applications (SALSA) [23]. Using this method, the measurement area of a material is defined by incident slits and receiving slits as shown in Fig. 6, which make it possible to determine the lattice plane spacing in a specific area by precisely measuring the Bragg diffraction from a particular crystalline lattice plane.

SALSA neutron diffractometer at the Institut Laue Langevin in France was used to measure the residual elastic strain [23]. Residual stress state of the weld was analysed from the measured elastic strain [24]. These measurements were made on the mid cross-sectional plane of a $300-\mathrm{mm}$ sample (plane ABCD) shown in Fig. 7, with the assumption that the stress state in the middle will be from steady-state welding process. Longitudinal, transverse, and normal strains were measured with assumption that these directions, by symmetry, are the principal stress directions. As shown in Fig. 7, the coordinate axes, LD represents the longitudinal direction, TD represent transverse direction, and ND represents normal direction.

The inter-planar spacing $(d)$ of the $\{311\}$ crystallographic plane was chosen for measurements of all the principal strain directions. The strain response of $\{311\}$ family of crystallographic planes in the face-centred cubic (FCC) lattice structure closely follows the macroscopic strain response over the measured gauge volume [23]. It was reported by Wang et al. [25]

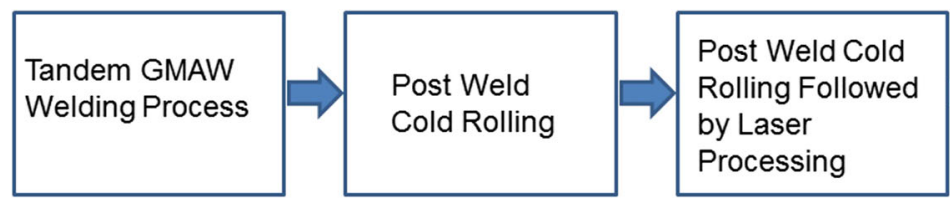

In determining residual stress using neutron diffraction, it is necessary to compare the crystal lattice spacing that is measured at the point of interest to lattice spacing of the material

that, in order to achieve accuracy better than the spatial resolution, it is necessary to perform a wall scan. Hence, the through-thickness scan was used for accurate positioning of the gauge volume within the plate. The gauge volume dimension was determined by using slits in front of the incoming beam and collimating the diffracted beam to maintain the through-thickness resolution. An incoming beam of $2 \times 2 \mathrm{~mm}^{2}$ was used for the longitudinal strain measurement, while a $2 \mathrm{~mm}$ collimator was used for the diffracted beam to achieve the desired spatial resolution. In these measurement conditions, the gauge volume at the measuring position was set to be approximately $2 \times 2 \times 2 \mathrm{~mm}^{3}$. In the transverse and normal strain measurement, an incoming beam of $2 \times 20 \mathrm{~mm}^{2}$ was used, with the assumption that the stress state and magnitude will remain constant in the welding direction. The increase in gauge volume along the welding direction, in these two directions, allows faster measurement with more grain sampling.

It is important to mention here that, in this research, measurements were made in two different times and, as such, two different measuring parameters were used:

1. The first phase (transient heating mode), where neutron incident beam of wavelengths, $1.62 \AA$, which gives a diffraction angle (2) of $95.99^{\circ}$ was used. The measurements were taken at $2 \mathrm{~mm}$ below the weld surface.

2. In the second phase where prolong heating was applied, neutron incident beam of wavelengths $1.6 \AA$, which gives a diffraction angle (2) of $93.2^{\circ}$, was used. The measurements were taken at $3 \mathrm{~mm}$ below the weld surface.

\subsubsection{Measurement of stress-free lattice parameter}

\begin{tabular}{|l|l|}
$\begin{array}{l}\text { Post Weld Cold } \\
\text { Rolling Followed } \\
\text { by Laser } \\
\text { Processing }\end{array}$ & $\begin{array}{l}\text { Cold Rolling after } \\
\text { Post Weld Cold } \\
\text { Rolling Followed by } \\
\text { Laser Processing }\end{array}$ \\
\hline
\end{tabular}

Fig. 2 Experimental flow chart 
Table 3 Welding parameters on narrow groove welds of 304L of austenitic steel plate

\begin{tabular}{|c|c|c|c|c|c|c|c|c|c|}
\hline \multirow[b]{2}{*}{ Pass } & \multicolumn{5}{|l|}{ Lead } & \multicolumn{2}{|l|}{ Trail } & \multirow{2}{*}{$\begin{array}{l}\text { Lead } \\
\text { Heat input } \\
\left(\mathrm{kJ} \mathrm{mm}^{-1}\right)\end{array}$} & \multirow{2}{*}{$\begin{array}{l}\text { Trail } \\
\text { Heat inpu } \\
\left(\mathrm{kJ} \mathrm{mm}^{-1}\right.\end{array}$} \\
\hline & $\begin{array}{l}\text { Travel speed } \\
\left(\mathrm{mm} \mathrm{s}^{-1}\right)\end{array}$ & $\begin{array}{l}\text { Wire feed speed } \\
\left.(\mathrm{m} \mathrm{min})^{-1}\right)\end{array}$ & $\begin{array}{l}\text { Average. } \\
\text { current (A) }\end{array}$ & $\begin{array}{l}\text { Average } \\
\text { volts }(\mathrm{V})\end{array}$ & $\begin{array}{l}\text { Wire feed speed } \\
\left.(\mathrm{m} \mathrm{min})^{-1}\right)\end{array}$ & $\begin{array}{l}\text { Average. } \\
\text { current (A) }\end{array}$ & $\begin{array}{l}\text { Average } \\
\text { volts (v) }\end{array}$ & & \\
\hline Root pass & 15.0 & 11 & 216.5 & 21.6 & 11 & 212.9 & 21.1 & 0.25 & 0.24 \\
\hline Fill 1 & 15.0 & 12 & 228.7 & 21.8 & 12 & 225.3 & 22.4 & 0.27 & 0.27 \\
\hline Cap pass & 11.7 & 10 & 222.5 & 22.5 & 10 & 214.8 & 22.7 & 0.34 & 0.33 \\
\hline
\end{tabular}

that is free of macroscopic stress. A comb-shaped sample of dimension $6 \mathrm{~mm} \times 6 \mathrm{~mm} \times 5 \mathrm{~mm}$ was machined out from the welded plate by electrical discharge machining as shown in Fig. 7. These dimensions of the individual comb would ensure relaxation of any macro residual stress field and will allow positional correction of the measured strain for compositional variation across the weld and also any changes in lattice parameter due to intergranular straining [26]. Therefore, it is important to have reference coupons as a function of position through the weld zone [27] when determining the residual stress. The stress-free lattice spacing $\left(d_{0}\right)$ was measured in all the three principal strain directions.

The lattice spacing $d$ is related to scattering angle $\varnothing$ by Bragg's law as shown in Eq. 2.

$\lambda=2 d_{\mathrm{hkl}} \sin \left(\frac{\varnothing}{2}\right)$ where $\lambda$ is the wavelength.

Gaussian fitting routine was used to fit the intensity profile and precise determination of the peak position. The stress-free lattice spacing $\left(d_{0}\right)$ measurements combined with the lattice spacing measurements were used to calculate strain $(\varepsilon)$ sing Eq. 3 .

$\varepsilon_{\mathrm{hk} 1}=\left(\frac{d_{\mathrm{hk} 1}}{d_{0 \mathrm{hkl}}}-1\right)$

where $\varepsilon$ is strain, hkl are the coordinate planes, $d$ is the lattice spacing, and $d_{0}$ is strain-free spacing (measured in the same plane).

The principal stress could be analysed once the strain is determined, using the Hooke's law for three-dimensional state of stress as shown in Eq. 4, using the appropriate elastic constants for the specific crystallographic plane.

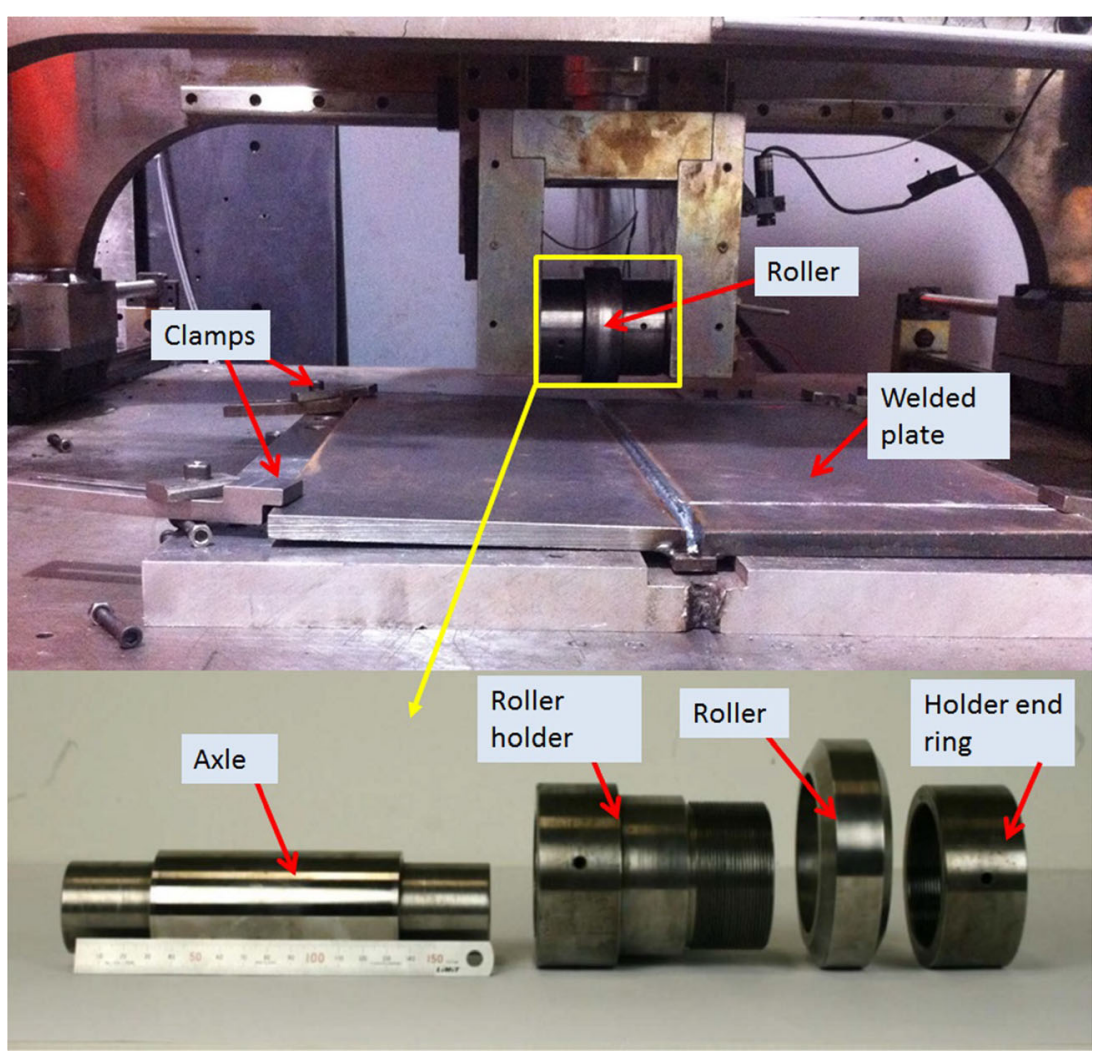

Fig. 3 Rolling rig setup showing the roller assembly 

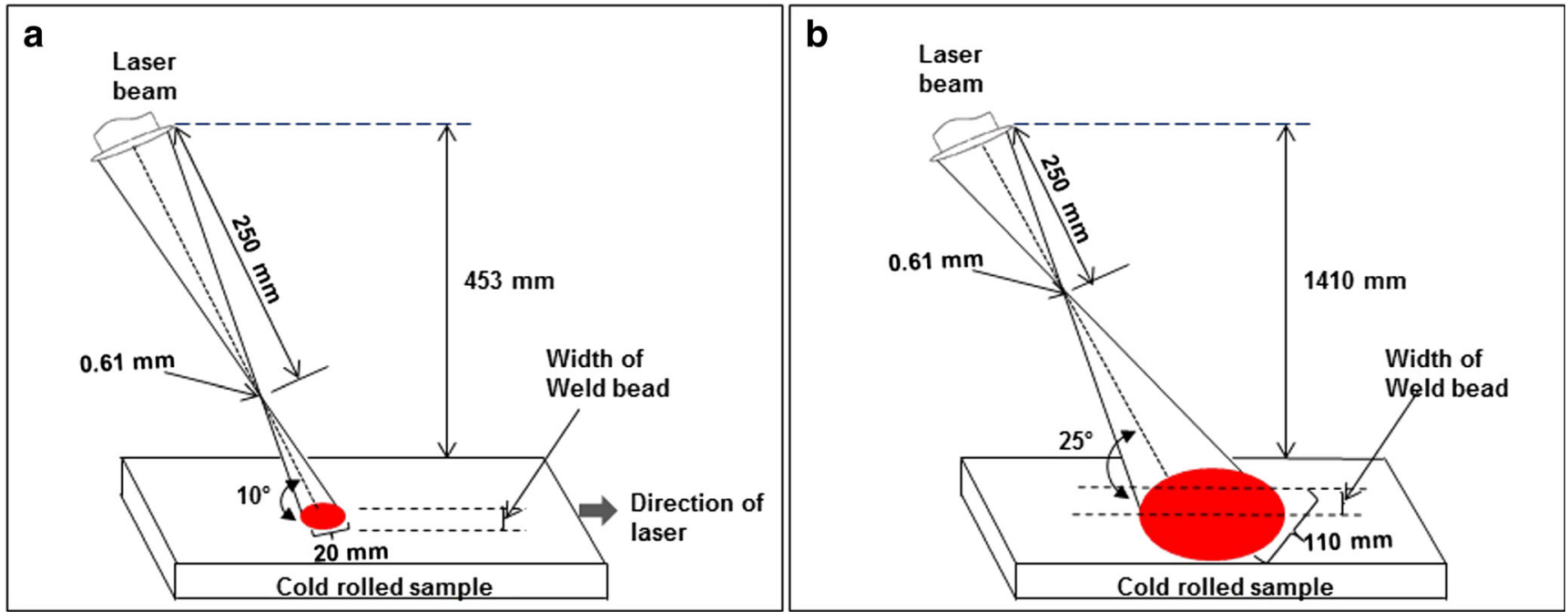

Fig. 4 Schematic setup of laser processing. a Transient heating mode. b Heating for prolonged period

$\sigma_{i i}=\frac{E}{(1+v)}\left[\varepsilon_{i i}+\frac{v}{(1-2 v)}\left(\varepsilon_{11}+\varepsilon_{22}+\varepsilon_{33}\right)\right]$

where $E$ and $v$ are the Young's modulus and Poisson ratio, respectively, and $i=1,2,3$ indicates the component of stress and strain relative to chosen to the principal strain directions. Elastic constants values of $\mathrm{E}=200 \mathrm{GPa}$ and $v=0.28$ [28] are used to calculate stress from measured strains.

\section{Results and discussions}

\subsection{Temperature-time plot (laser application)}

Figure 8 shows the weld thermal cycle for the two phases in laser processing. The first phase (transient heating mode) used a constant beam diameter of $20 \mathrm{~mm}$. Laser power of $1.0 \mathrm{~kW}$ and a travel speed of $0.3 \mathrm{~m} \mathrm{~min}^{-1}$ was used. At the cap pass, this gives a peak temperature of approximately $649{ }^{\circ} \mathrm{C}$ $(922 \mathrm{~K})$, while at root pass, the temperature was $330{ }^{\circ} \mathrm{C}$ (603 K) (Fig. 8a).

In the second phase, the sample was gradually heated up to $800{ }^{\circ} \mathrm{C}$ using a controlling laser power at constant larger beam

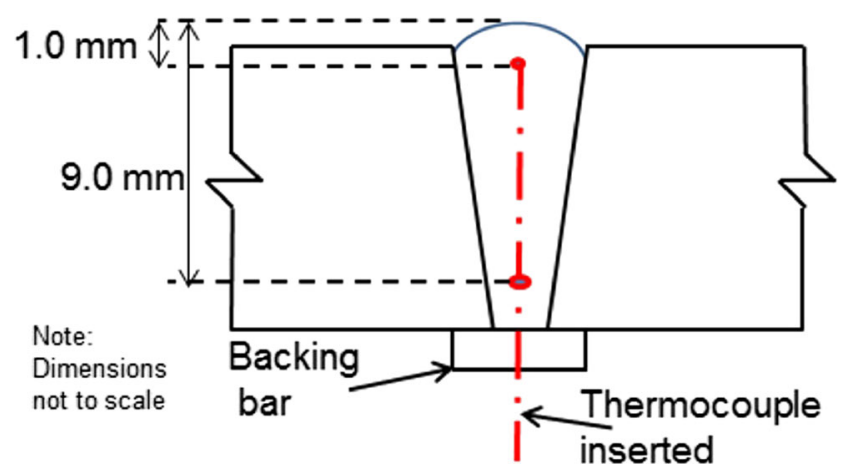

Fig. 5 Positions of the thermocouple in weld metal cross section diameter of $110 \mathrm{~mm}$ (Fig. 8b). This temperature was selected based on the fact that recrystallization temperature of metal or alloy is between one third and one half of the absolute melting temperature [29].

\subsection{Microstructure}

Figure 9 shows the SEM images of the different processing condition. However, for further understanding of the microstructures, the grain structure was analysed using electron back-scatter diffraction (EBSD) and the data were collected over an area of $316 \mu \mathrm{m} \times 234 \mu \mathrm{m}$ with step size $0.73 \mu \mathrm{m}$. Figure 10a shows a dendritic and columnar grain structure. This is attributed to the fact that during weld metal solidification, grains tend to grow in the direction perpendicular to pool boundary. This dendritic solidification of the weld metal results in segregation of alloying elements within the grain structures which would lead to the formation of localised region with relatively low corrosion protection. Columnar grain growth was reported to influence mechanical properties [30] and microstructural features, such as microsegregation [31]. The effect of post-weld cold rolling did not show any major transformation in the grain structure, but elongation of the grain size was evident as shown in Fig. 10b. Post-weld cold rolling followed by laser processing (in the first phase) shows a minimal refinement of microstructure (Fig. 10c). This indicated that the re-crystallisation is not complete because the transient thermal cycle is not sufficient to supply enough energy to sustain the entire recrystallization kinetics. Post-weld cold rolling followed by laser processing in the second phase shows a significant grain refinement close to the cap pass as shown in Fig. 10d. This grain refinement obtained would increase the strength and toughness of the material which is lower in as-welded state due to the formation of dendritic grain structure. 


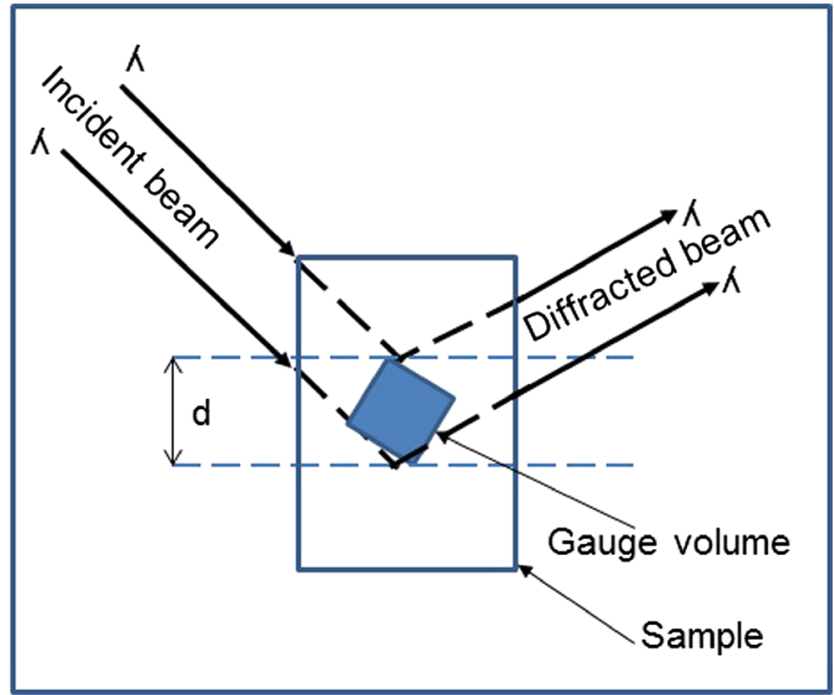

Fig. 6 Sketch showing the gauge volume in strain-scanning method

In the grain size measurement, the average grain size of the as-welded sample was $14.81 \mu \mathrm{m}$ at cap pass. The average grain size of the post-weld rolling sample taken at the same position was found to be $19.78 \mu \mathrm{m}$. Similarly, average grain size of $11.00 \mu \mathrm{m}$ was found when post-weld cold rolling followed by laser processing (in first phase) was applied on the sample at the same position while average grain size of $5.10 \mu \mathrm{m}$ was found when post-weld cold rolling sample was followed by laser processing in second phase. Generation of the recrystallized microstructure $(5.10 \mu \mathrm{m})$ with large proportion of high-angle grain boundaries would increase the strength and toughness of the material which is lower in aswelded dendritic grain structure state.

\subsection{Hardness distribution}

\subsubsection{Effect of post-weld cold rolling on hardness}

Figure 11a shows the hardness distribution at the cap pass of the welded samples with different processing conditions. Hardness values are lowest in the parent metal but sharply increases in the heat-affected zone, and at the weld metal, the hardness remains fairly uniform at the cap pass. Postweld cold rolling increases the hardness value from 219 to $299 \mathrm{HV}$ at the weld metal. This effect of post-weld cold rolling is predictable, since work hardening is an inevitable consequence of the plastic deformation induced during rolling. The HAZ in all the samples were harder than weld metal and the parent metal. This could be attributed to the strain hardening of the HAZ.

A hardness scan was performed from the cap pass to the root pass as shown in Fig. 11b. The effect of cold working was observed throughout the entire thickness of the material when the post-weld cold rolling was performed. This is due to large number of slip systems in a FCC lattice. The closely packed planes make it easier for planes of atoms to slide by each other on application of load. However, up to about $4 \mathrm{~mm}$ below the cap, the effect was very significant due to direct contact between roller and cap pass, indicating more plastic deformation at that region.

\subsubsection{Effect of post-weld cold rolling followed by laser processing on hardness}

Post-weld cold rolling followed by laser processing in the first phase shows decrease in hardness values (299

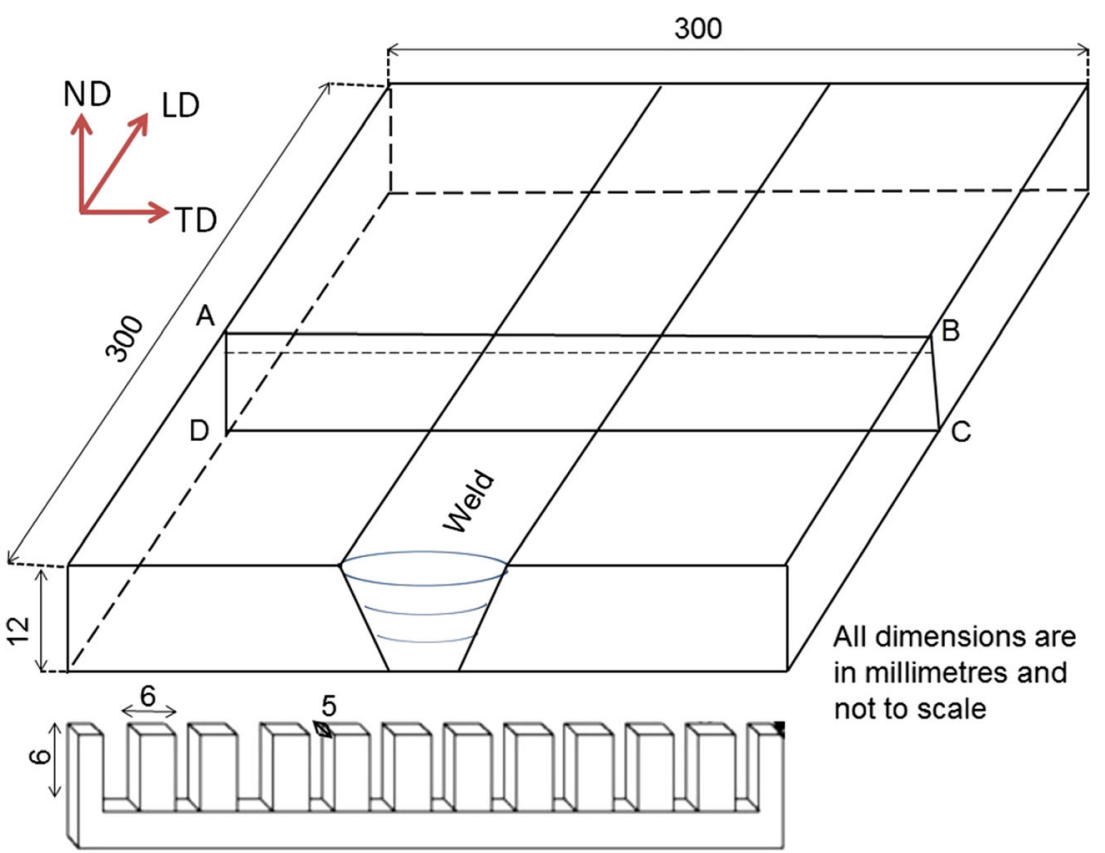

Fig. 7 Schematic diagram of the multi-pass welded plate showing lines of measurement with reference comb 


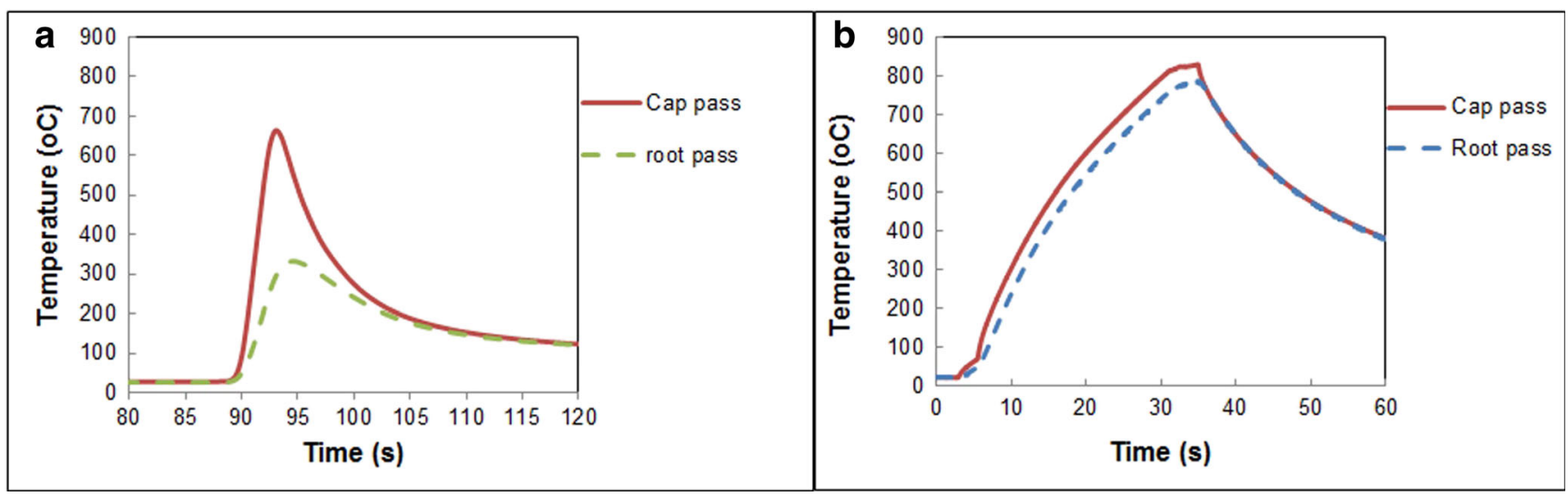

Fig. 8 Thermal cycles of laser processing. a First phase. b Second phase

to $280 \mathrm{HV}$ ) at the cap pass Fig. 11a. This diminished in hardness values is attributed to change in microstructure. Although this thermal energy applied was not sufficient to supply enough energy to sustain a complete recrystallization kinetic. However, in the second phase, the laser application shows a significant decrease in hardness values (299 to $241 \mathrm{HV}$ ) at the cap pass and the effect continues throughout the thickness (Fig. 11b). This indicates that the thermal energy applied was sufficient to supply enough energy to sustain a complete recrystallization kinetic as it was evident in EBSD studied shown in Fig. 10d.

\subsection{Residual stress}

\subsubsection{Residual stresses across the as-welded sample}

Figure 12 shows the distribution of the stresses in principal directions (longitudinal, transverse, and normal). As shown, both the weld zone and HAZ show mainly tensile stress (aswelded). In the longitudinal direction, the stress has a maximum value of $395 \mathrm{MPa}$ at the weld metal centreline. With increasing distance from the weld centreline as shown in the figures, the temperature declines sharply which lead to uneven heat input between the weld metal and base metal. These
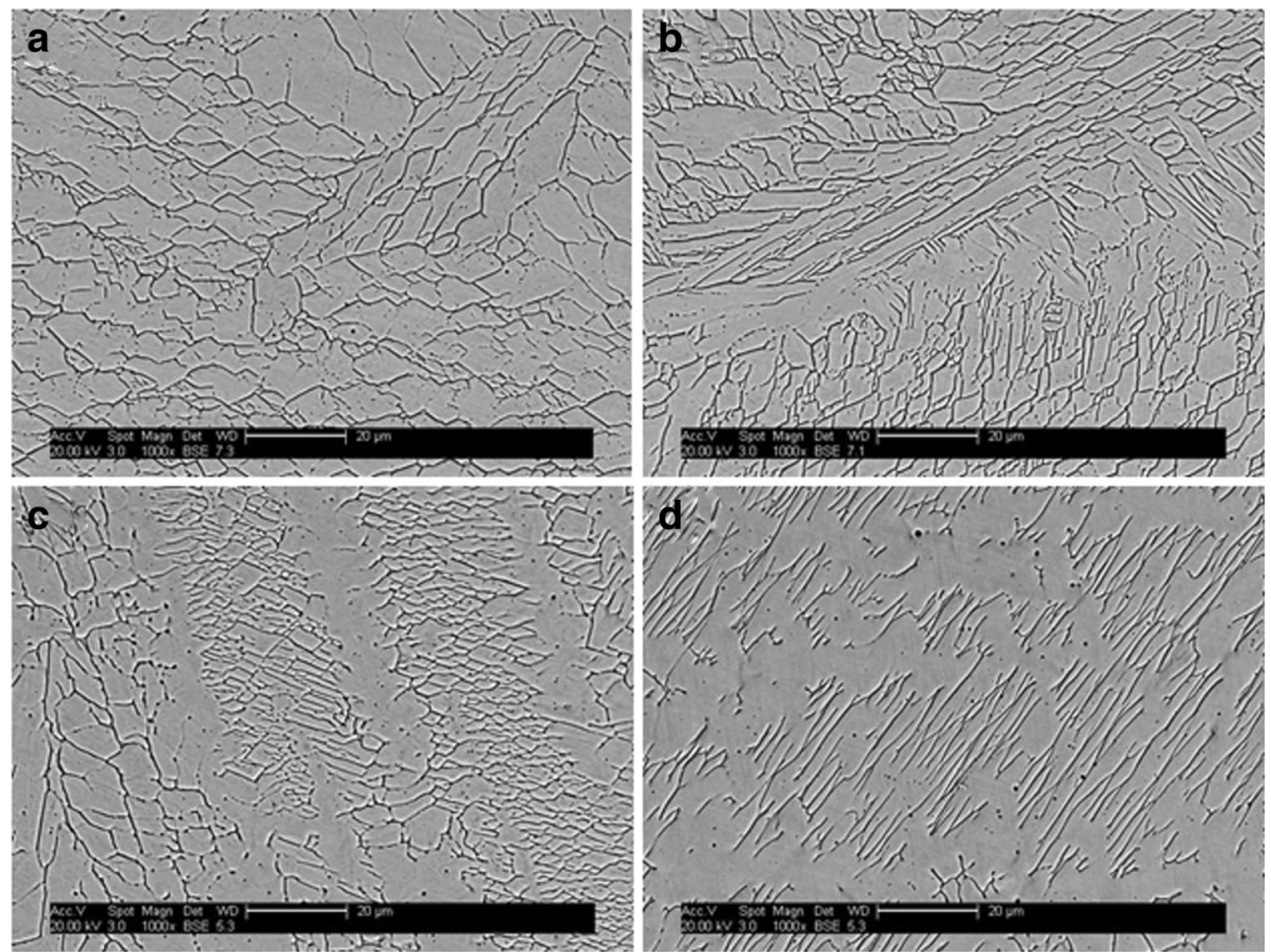

Fig. 9 SEM images. a As-welded. b Post-weld cold rolled. c Post-weld cold rolling followed by laser in first phase. d Post-weld cold rolling followed by laser in second phase 

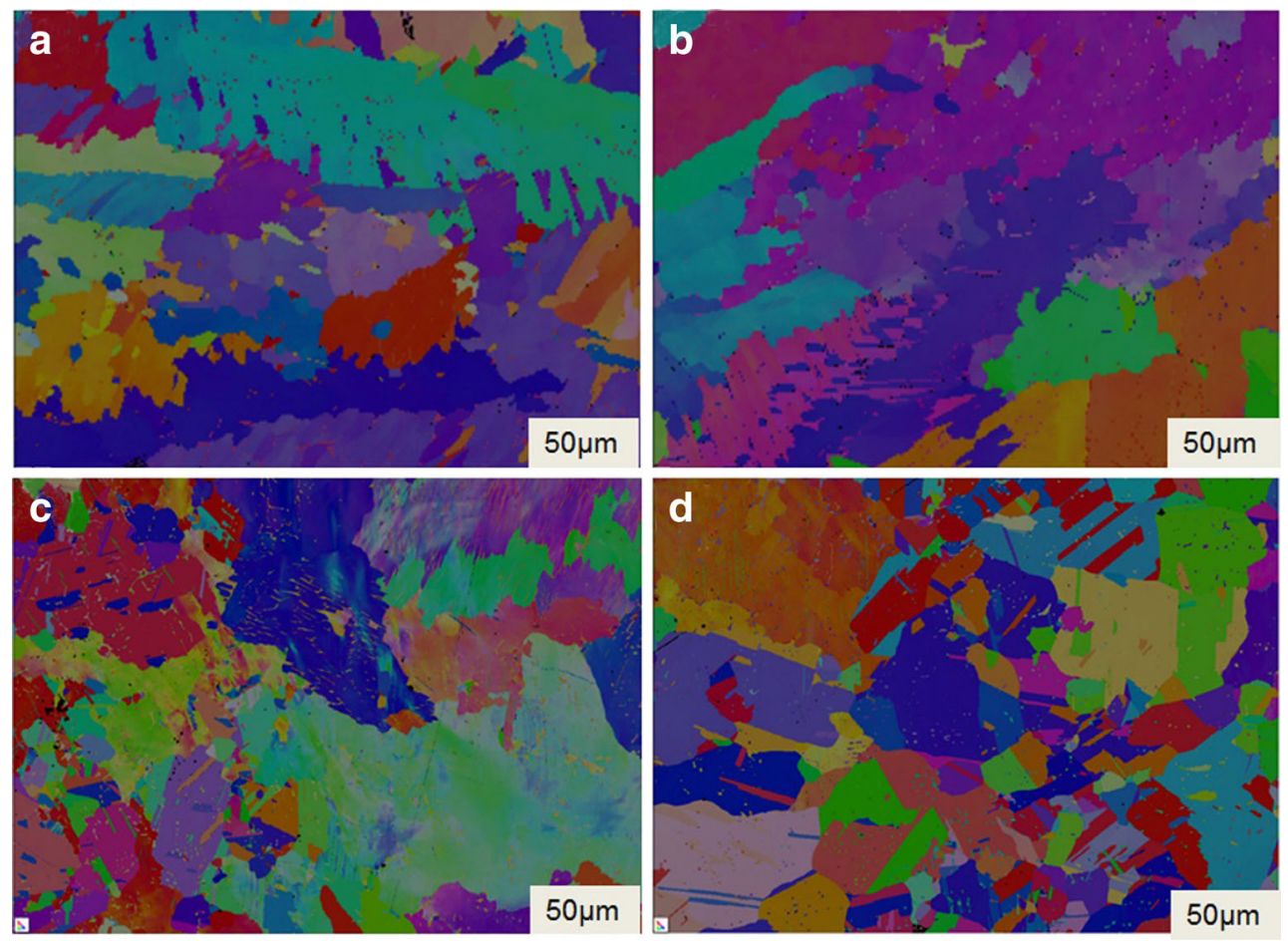

Fig. 10 EBSD. a As-welded. b Post-weld cold rolling. c Post-weld cold rolling followed by laser in first phase. d Post-weld cold rolling followed by laser in second phase

thermal contractions of the material in the high-temperature zone have been restricted by the materials around it, resulting in the tensile stress. The variation in the stress profile of the weld metal can be attributed to the fact that fusion zone is within the arc centre and is predominately affected by the heat input, traveling speed, and other welding parameters.

It was observed that the transverse residual stresses are mainly tensile with a maximum value of $158 \mathrm{MPa}$ at the weld metal centreline. As shown, this magnitude is lower than that of longitudinal stress direction. This could be attributed to the fact that during the cooling stage, solidification shrinkage is restrained by base metal in the transverse direction, which also contributes to the formation of the tensile stress after welding. Another possible reason of lower transverse stress could be the propagation of heat in transverse direction. Heat transfer is faster in transverse direction than in longitudinal direction; hence, the heat quantity transferred in transverse direction is more than in longitudinal direction which may also affect the stress distribution in transverse direction.

Comparing the normal stress value to the longitudinal and transverse residual stress, the stress in normal direction is smaller. Maximum value obtained at weld centreline was $86 \mathrm{MPa}$. The weld zone shows tensile residual stress and the HAZ and base metal shows compressive residual stress. With increasing distance from weld centreline, the stress decreases gradually and then declines to zero. The tensile residual stress was observed around the weld centreline because of the solidification of weld metal and constriction of around base metal.

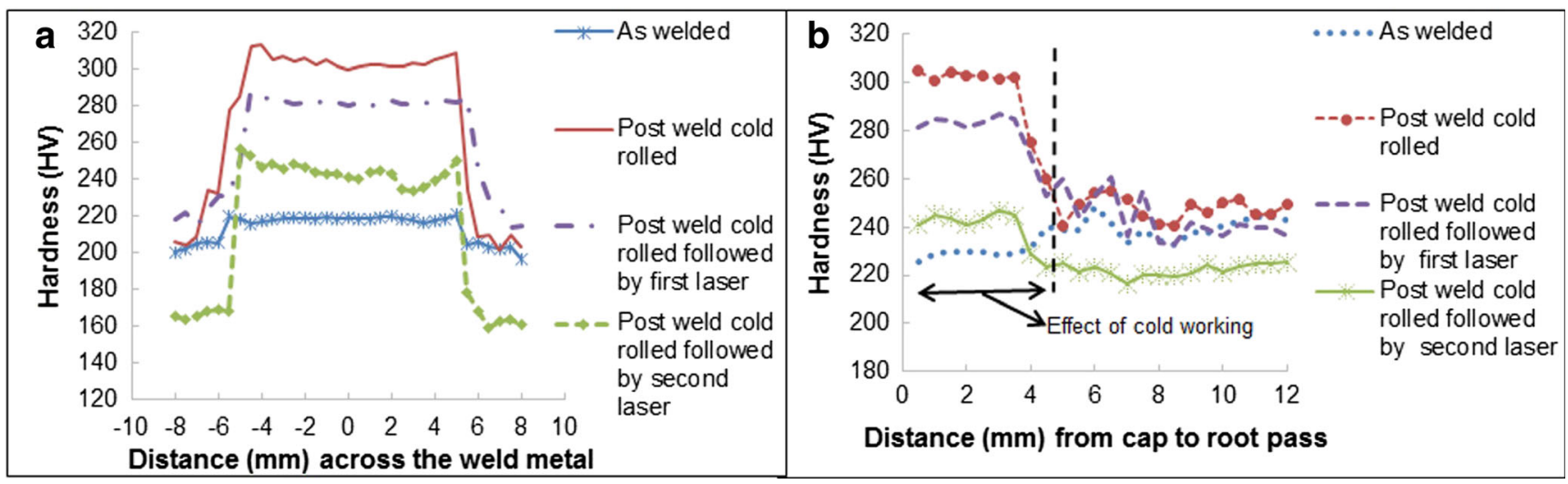

Fig. 11 a Hardness scan position along the weld metal and $\mathbf{b}$ hardness profile 


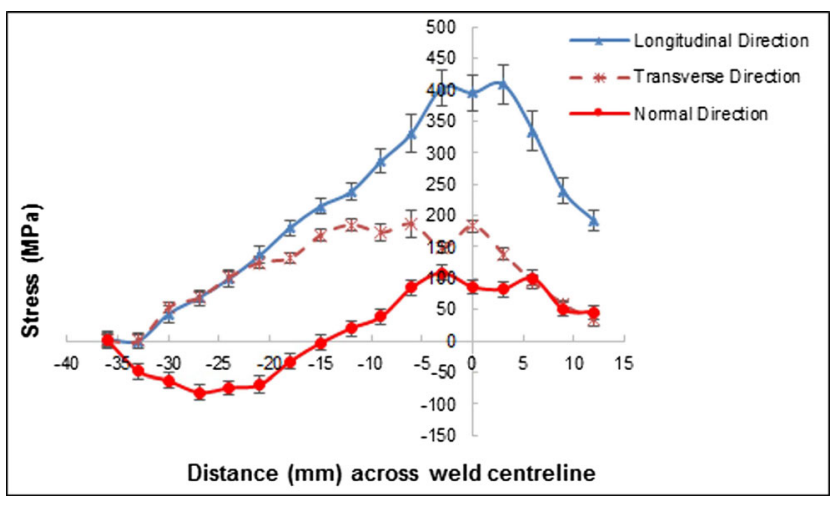

Fig. 12 As-welded sample showing stresses in principal directions (measured $2 \mathrm{~mm}$ below the weld surface)

\subsubsection{Effect of post-weld cold rolling}

A flat roller of $30 \mathrm{~mm}$ width was used which determines the extent to which localised plastic strain is induced and thereby generation of compressive longitudinal stress (Fig. 13a). However, the compressive zone width is narrower than the width of roller because the contact area of the roller is smaller compared to the width of roller. Hence, rolling causes plastic deformation around that region of the weld which is approximately $15 \mathrm{~mm}$ in width.

As shown in Fig. 13a, post-weld cold rolling (measurement was taken at $2 \mathrm{~mm}$ below the weld surface) has changed the longitudinal residual stress state causing it to become compressive around the weld metal (from peak tensile stress of $395 \mathrm{MPa}$ to compressive stress of $80 \mathrm{MPa}$ ). Application of rolling to the welded joints causes yielding of material in the weld region, thereby relieving the residual stresses that may exist in the region. These rolling processes compress the material in the direction normal to the weld's surface, thereby causing it to expand in the plane of the weld, relaxing any tensile residual stresses in the plane.

\subsubsection{Effect of post-weld cold rolling followed by laser processing}

In the first phase, laser processing after cold rolling has shown an increase in the longitudinal residual stress from compressive stress of $80 \mathrm{MPa}$ to peak tensile stress of $479 \mathrm{MPa}$ (Fig. 13a). Similarly, in the second phase, laser processing after cold rolling (measurement was taken at $3 \mathrm{~mm}$ below the weld surface) has modified the longitudinal residual stress from peak compressive stress of $80 \mathrm{MPa}$ in Fig. 13a to peak tensile stress of $536 \mathrm{MPa}$ in Fig. 13b indicating a high-thermal input and non-uniform cooling of the material, thus generating inhomogeneous plastic deformation and tensile residual stresses. This necessitates another novel idea of cold rolling after laser processing to redistribute and eliminate the tensile residual stress which would have formed during laser processing.

\subsubsection{Effect of cold rolling after post-weld cold rolling followed by laser processing}

Further cold rolling after post-weld cold rolling followed by laser processing has changed the longitudinal residual stress state once again to become compressive around the weld metal (from peak tensile stress of $536 \mathrm{MPa}$ to compressive stress of $162 \mathrm{MPa}$ in Fig. 13b). The presence of this compressive stress component would likely inhibit crack propagation across the weld under longitudinal fatigue loading which is essential for structural integrity of an engineering or structural component.

\section{Conclusion}

This paper investigates the possibilities of using high-pressure rolling and laser processing to modify the residual stress distribution and microstructure in multi-pass welds of $304 \mathrm{~L}$ austenitic stainless steel. It can therefore be deduced from the

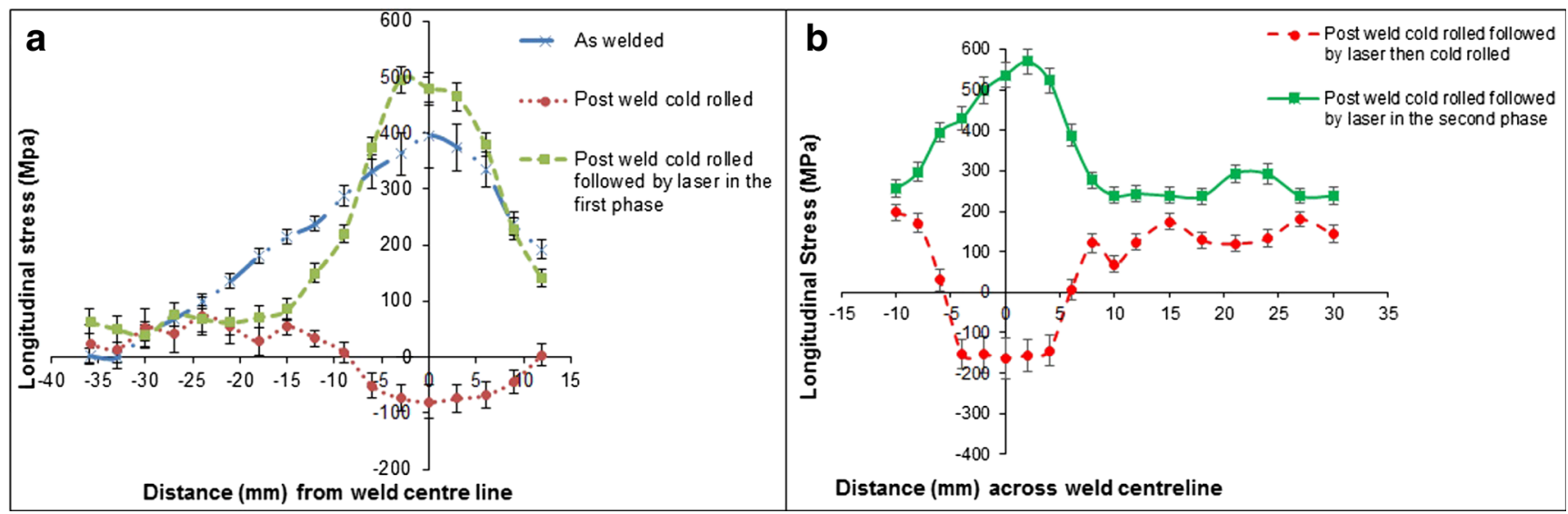

Fig. 13 Residual stress profile across the weld sample with different processing conditions. a First phase of the measurement at measured 2 mm below the weld surface. $\mathbf{b}$ Second phase of the measurement at measured $3 \mathrm{~mm}$ below the weld surface 
experiments that the modified laser processing followed by cold rolling resulted in generation of complete recrystallized microstructure with compressive residual stress state. Generation of this compressive stress state is beneficial in improving the structural integrity of a component as most of the inservice deterioration starts with a surface flaw. The generation of the recrystallized microstructure with large proportion of high-angle grain boundaries would increase the strength and toughness of the material which is lower in as-welded dendritic grain structure state.

This recrystallized grain structure is also important in this material since the change in dendritic structure to a kind of equiaxed grains structure will limit the $C_{\mathrm{r}}$ segregation in the welds which would have resulted in formation of corrosion microcells.

In summary, this novel processing clearly demonstrates the improvement of structural features that can be obtained in traditional welded structural alloys. However, optimisation of the post-weld cold rolling and laser processing would be required for different alloy systems. It would be advisable to consider the material's work hardening characteristics and the effects of deformation on metallurgical and constitutive properties, if post-weld cold rolling is to be applied.

Acknowledgments The authors are grateful for the funding provided by Petroleum Development Trust Fund in Nigeria, under the PTDF scholarship scheme no. PTDF/E/OSS/PHD/SJ/391/11. The authors are also thankful to Mr. Brian Brooks and Mr Flemming Nielsen for technical support in laboratory. Dr. Supriyo Ganguly acknowledges support from EPSRC through grant numbers EP/J017086/1 and EP/K030884/1.

Open Access This article is distributed under the terms of the Creative Commons Attribution 4.0 International License (http:// creativecommons.org/licenses/by/4.0/), which permits unrestricted use, distribution, and reproduction in any medium, provided you give appropriate credit to the original author(s) and the source, provide a link to the Creative Commons license, and indicate if changes were made.

\section{References}

1. Cary, H. B. (1981) Modern welding technology, 2nd. ed. Amercian Welding Society, USA, pp. 497-498

2. Liao MT, Chen WJ (1998) The influence of shielding gas on notch toughness of stainless steel weld metals. Mater Manuf Process 13(4):565-573

3. Lee W, Lin C, Liu C, Cheng C (2007) Effects of strain rate and welding current mode on microstructural properties of SUS 304L PAW welds. J Mater Process Technol 183(2-3):183-193

4. Parker AP (1982) Stress intensity factors, crack profiles, and fatigue crack growth rates in residual stress fields. In: Residual stress effects in fatigue. ASTM STP 776, Philadelphia, pp. 13-31

5. Formby CL, and Griffiths JR (1977) The role of residual stress in the fracture of steel. In: Residual stresses in welded construction and their effects, vol. 1. 15-17 November, London, The Welding Institute, Cambridge, pp. 359-374
6. Leggatt RH (2008) Residual stresses in welded structures. Int J Press Vessel Pip 85(3):144-151

7. Read DT (1989) Measurement of applied J-integral produced by residual stress. Eng Fract Mech 32(1):147-153

8. Turski M, Bouchard PJ, Steuwer A, Withers PJ (2008) Residual stress driven creep cracking in AISI type 316 stainless steel. Acta Mater 56(14):3598-3612

9. Francis JA, Bhadeshia HKDH, Withers PJ (2007) Welding residual stresses in ferritic power plant steels. Mater Sci Technol 23(9): $1009-1020$

10. Mullins J, Gunnars J (2011) Deformation histories relevant to multipass girth welds: temperature, stress and plastic strain histories. Riva del Garda, Trento (ed)

11. Lippold JC, Kotecki DJ (2005) Welding metallurgy and weldability of stainless steels. John Wiley \& Sons Inc, Hoboken, NJ

12. Panchal VD (2013) Relieving stress in stainless steels. World Pumps 2013(1):28-32

13. Rao D, Chen L, Ni C (2006) Vibratory stress relief of welded structure in China. Mater High Temp 23(3-4):245-250

14. Yanagida N, Koide H. (2006) Residual stress improvement in multi-layer welded plates using water-shower cooling during welding process. Nihon Kikai Gakkai Ronbunshu, A Hen/ Transactions of the Japan Society of Mechanical Engineers, Part $A$, vol. 72 , no. 11 , pp. $1631-1638$

15. Liu W, Tian X. Zhang X (1996) Preventing weld hot cracking by synchronous rolling during welding. Welding Journal (Miami, Fla), vol. 75 , no. 9 , pp. 297 -s

16. Altenkirch J, Steuwer A, Withers PJ, Williams SW, Poad M, Wen SW (2009) Residual stress engineering in friction stir welds by roller tensioning. Sci Technol Weld Join 14(2):185-192

17. Coules HE, Colegrove P, Cozzolino LD, Wen SW, Ganguly S, Pirling T (2012) Effect of high pressure rolling on weld-induced residual stresses. Sci Technol Weld Join 17(5):394-401

18. Jibrin S, Supriyo G, Harry C, Thilo P (2015) Comparative study of evolution of residual stress state by local mechanical tensioning and laser processing of ferritic and austenitic structural steel welds. J Mech Eng Autom 5(1):33-42

19. Sule J, Ganguly S, Coules H, Pirling T (2015) Application of local mechanical tensioning and laser processing to refine microstructure and modify residual stress state of a multi-pass 304L austenitic steels welds. J Manuf Process 18:141-150

20. Kou S (2003) Welding metallurgy, 2nd edn. John Wiley \& Sons, Inc, Hoboken

21. Hutchings MT (2005) Introduction to the characterization of residual stress by neutron diffraction. CRC Press, Boca Raton

22. Withers PJ, Preuss M, Steuwer A, Pang JWL (2007) Methods for obtaining the strain-free lattice parameter when using diffraction to determine residual stress. J Appl Crystallogr 40(5):891-904

23. Pirling T, Bruno G, Withers PJ (2006) SALSA-A new instrument for strain imaging in engineering materials and components. Mater Sci Eng A 437(1):139-144

24. Withers PJ, Turski M, Edwards L, Bouchard PJ, Buttle DJ (2008) Recent advances in residual stress measurement. Int J Press Vessel Pip 85(3):118-127

25. Wang X, Spooner S, Hubbard CR (1998) Theory of the peak shift anomaly due to partial burial of the sampling volume in neutron diffraction residual stress measurements. J Appl Crystallogr 31(1): $52-59$

26. Rogante $M(2000)$ Stress-free reference sample: the problem of the determination of the interplanar distance d0. Phys B Condens Matter 276-278:202-203

27. Holden TM, Suzuki H, Carr DG (2006) Macroscopic stress measurements by neutron diffraction and the part played by the "stressfree" reference. ISIJ Int 46(7):959-965

28. Moat RJ, Stone HJ, Shirzadi AA, Francis JA, Kundu S, Mark AF, Bhadeshia HKDH, Karlsson L, Withers PJ (2011) Design 
of weld fillers for mitigation of residual stresses in ferritic and austenitic steel welds. Sci Technol Weld Join 16(3): 279-284

29. William DC (2007) Material science \& engineering: an introduction, 7th ed, USA
30. Flemings MC (1974) Solidification processing. McGraw-Hill, New York

31. Feest EA, Doherty RD (1973) Dendritic solidification of $\mathrm{Cu}-\mathrm{Ni}$ alloys: part II. The influence of initial dendrite growth temperature on microsegregation. Metall Trans 4(1):125-136 